\title{
Hypertension and its associated factors in Hosanna town, Southern Ethiopia: community based cross-sectional study
}

\author{
Likawunt Samuel Asfaw ${ }^{1 *}$, Samuel Yohannes Ayanto ${ }^{2}$ and Fiseha Laemengo Gurmamo ${ }^{3}$
}

\begin{abstract}
Objectives: This study was conducted to determine the prevalence of hypertension and its associated factors among residents of Hosanna town in Hadiya Zone.

Results: The overall prevalence of hypertension was 30\% among the study participants. Out of the study participants who were identified as being hypertensive, only $24.6 \%$ knew their hypertensive status. The odds of being hypertensive is significantly higher among males when compared to females (adjusted odds ratio (AOR) 1.9, confidence interval (CI) 1.14-3.23) and married participants as compared to their unmarried counterparts (AOR 4.1; Cl 1.10-16.18). High prevalence and increased risks for hypertension were noted among the study participants in the study area. The experiences of aerobic physical activities were reported only in $22.9 \%$ of the study participants. These evidences may suggest the need for urgent interventions.
\end{abstract}

Keywords: Cardio-vascular disorders, Hypertension, Non-communicable diseases, Obesity

\section{Introduction}

Hypertension is persistent elevation of $\mathrm{BP}$ above this normal range [1] and is classified into different groups based on causes and degree of severity [2-5].

Hypertension has become major public health problem of human being globally. It is estimated to cause 1 billion deaths, which is about $12.8 \%$ of all deaths worldwide [6, 7]. In Africa $46 \%$ of its adult population had hypertension, which is the highest for regions in the world $[6,8]$. Similarly, the figure for sub-Saharan Africa was 47.5\% [9, 10].

Ethiopia shares similar profile like most sub-Saharan African countries. Findings of World Health Organization on prevalence of hypertension showed that $35.2 \%$ of the community in Ethiopia has high likelihood of being hypertensive [6]. To a large extent hypertension is associated with environmental, rapid urbanization and life style changes $[11,12]$. There are controversial opinions on the

\footnotetext{
*Correspondence: getliku@gmail.com

1 Department of Nursing, Hosanna College of Health Sciences, Post Box 159, Hosanna, Ethiopia

Full list of author information is available at the end of the article
}

association between hypertension and gender. In prevalence study in rural Bareilly there was no significant difference between males and females [13, 14]. However, in most global and Ethiopian studies hypertension is more prevalent among males than females [14-16]. Obesity, tobacco smoking and harmful alcohol use are significantly associated with hypertension [17-25]. Majority of previous studies done in Ethiopia were based on hospital records and reported contradicting opinions. Therefore, the aim of this study was to assess the prevalence and associated factors of hypertension in a community sample.

\section{Main text \\ Methods \\ Study design and setting}

The study was conducted in Hosanna town, the capital of Hadiya Zone, located at a distance of $232 \mathrm{~km}$ southwest of Addis Ababa, the capital of Ethiopia. There were 16,707 Households in the town. Community based crosssectional study was carried out among residents of the town, in May 2014 [26]. 


\section{Sample size and sampling technique}

The desired sample size for our study was estimated by taking prevalence of hypertension (35.2\%) from previous study [6], 95\% confidence level, 5\% margin of error and design effect of 1.5. Consequently, the final sample size was determined to be 525 participants. The sample size was calculated using the formula;

$$
\begin{aligned}
& \mathrm{n}=\frac{\mathrm{Z} \frac{\alpha}{2} \mathrm{P}(1-\mathrm{P})}{\mathrm{d}^{2}} \\
& \mathrm{n}=\frac{(1.96)^{2} 0.35(1-0.35)}{(0.05)^{2}}=350(1.5)=525
\end{aligned}
$$

The final sample size was proportionally allocated to sub-administrative units of the town. Sampling frame was created for each sub-unit and randomly generated numbers were used to select the households. Simple random sampling technique was used to select the households from each unit. From each of the selected households, one participant satisfying inclusion criteria was selected by lottery method.

\section{Inclusion and exclusion criteria}

Individuals below the age of 25 years, those above the age of 64 years, pregnant mothers and disabled people were excluded from the study. The primary reason for excluding pregnant women and individuals above the age of 64 is that they are most at risk for hypertension and their inclusion could preclude generalization. Contrarily, young people below the age of 25 years are at low risk for hypertension and disabled people were not eligible for exercise related inquiries relevant for our research which might affect the true finding in the population.

\section{Data collection instrument and measurement}

The WHO STEPS instrument and global physical activity questionnaire (GPAQ) were modified and used [27, 28]. The tool has three major parts: socio-demographic characteristics, behavioral profile and physical measurements. The modified instrument was translated into the local language, Amharic. Data were collected through interviewer administered and physical body measurement techniques using structured questionnaire.

Two days training was provided for data collectors and supervisors regarding research ethics, data collection procedures and contents of the instrument to increase the quality of our data. Supportive supervision was carried out by the supervisors on a daily basis during the data collection period. The completed questionnaire had been checked daily for its completeness and consistency.

The blood pressure was measured after the participant had rested for at least $5 \mathrm{~min}$. Two measurements at 10 min interval were taken from right arm by a mercury sphygmomanometer. The mean value of the two measurements was recorded as a BP for each participant.

Height was measured using fixed height measuring board in upright position with participant's heel, shoulder and buttock touching the vertical board behind. The measurement value was recorded to the nearest millimeter. Weight was measured using calibrated weight scale where participants being in light clothing and barefooted. Its reading was taken to the nearest $0.1 \mathrm{~kg}$. Waist circumference measurement was taken at midpoint between lower measure margin of the last plain rib and top of iliac crest using non elastic tape meter. Each participant was told to take little deep, natural breath before taking the measurement. The measurement was taken at the end of normal expiration, when the lungs are at their residual capacity.

\section{Data analysis techniques}

The collected data were cleaned and entered to Epi-Data version 3.2, and exported to STATA version 12.0 for analysis. Descriptive statistics and multivariable logistic regression were used to analyze the data. Candidate variables with $P$ value $<0.2$ in Bivariable model were entered to multivariable model to adjust for predictors. The $95 \%$ $\mathrm{CI}$ for the corresponding Odds Ratio (OR) was used to assess the degree of associations at $(P<0.05)$ to declare significance.

\section{Variables and definitions}

The participant was regarded as hypertensive when an average $\mathrm{SBP} \geq 140 \mathrm{mmHg}$, and/or $\mathrm{DBP} \geq 90 \mathrm{mmHg}$ was recorded and/or the participant is currently on antihypertensive medications.

The body mass index (BMI) was interpreted according to WHO classification as underweight $(\mathrm{BMI}<18.5 \mathrm{~kg} /$ $\mathrm{m}^{2}$ ), normal (BMI $18.5-24.9 \mathrm{~kg} / \mathrm{m}^{2}$ ), overweight (BMI $\left.25.0-30.0 \mathrm{~kg} / \mathrm{m}^{2}\right)$ and obese $\left(\right.$ BMI $\left.>30.0 \mathrm{~kg} / \mathrm{m}^{2}\right)$.

Men having waist circumference greater than $94 \mathrm{~cm}$ were identified as having increased risk for hypertension and metabolic complications whereas men having waist circumference greater than $102 \mathrm{~cm}$ were identified as having substantially increased risk for hypertension and metabolic complications.

Women having waist circumference greater than $80 \mathrm{~cm}$ were identified as having increased risk for hypertension and metabolic complications whereas women having waist circumference greater than $88 \mathrm{~cm}$ were identified 
as having substantially increased risk for hypertension and metabolic complications.

\section{Results}

A total of 524 participants were involved in the study which gives response rate of $99.8 \%$. The majority (52.9\%) of study participants were males. The mean age of the study participants was $35.4 \pm 7.7$ SD years. Majority $(38.5 \%)$ of participants were government employee. Nearly half (48.8\%) of the study participants were College or University graduates. The average monthly income of the study participants was $72.31 \pm 916.33$ USD. The average number of individuals per household was nearly 6 (Table 1). One hundred twenty-two (23.3\%) participants reported their experience of alcohol consumption on daily basis and 77 (14.7\%) participants were smokers.

\section{Physical measurements}

The mean systolic and diastolic BP reading for the study participants were $118.37 \pm 13.42$ (SD) $\mathrm{mmHg}$ and $74.24 \pm 11.18$ (SD) $\mathrm{mmHg}$ respectively. The prevalence of hypertension among the study participants was $30 \%$ (CI 26.0-33.8\%) out of which only 39 (24.6\%) knew their hypertensive status (Fig. 1).

Table 1 Socio-demographic characteristics of study participants in Hosanna town 2014

\begin{tabular}{|c|c|c|}
\hline Characteristics & Number & Percent \\
\hline \multicolumn{3}{|l|}{$\operatorname{Sex}(n=524)$} \\
\hline Male & 277 & 52.9 \\
\hline Female & 247 & 47.1 \\
\hline \multicolumn{3}{|l|}{ Age $(n=524)$} \\
\hline $25-34$ & 102 & 19.5 \\
\hline $35-44$ & 273 & 52.1 \\
\hline $45-54$ & 110 & 21.0 \\
\hline $55-64$ & 39 & 7.4 \\
\hline \multicolumn{3}{|l|}{ Marital status $(n=524)$} \\
\hline Single & 195 & 37.1 \\
\hline Married & 192 & 36.6 \\
\hline Divorced & 106 & 20.2 \\
\hline Widowed & 31 & 5.9 \\
\hline \multicolumn{3}{|l|}{ Education $(n=524)$} \\
\hline No formal education & 24 & 4.6 \\
\hline Primary education & 130 & 24.8 \\
\hline Secondary education & 115 & 21.9 \\
\hline College/university & 255 & 48.7 \\
\hline \multicolumn{3}{|l|}{ Income $(n=524)$} \\
\hline$<54$ USD & 132 & 25.2 \\
\hline 55-91 USD & 233 & 44.5 \\
\hline 92-109 USD & 30 & 5.7 \\
\hline > 109 USD & 129 & 24.6 \\
\hline
\end{tabular}

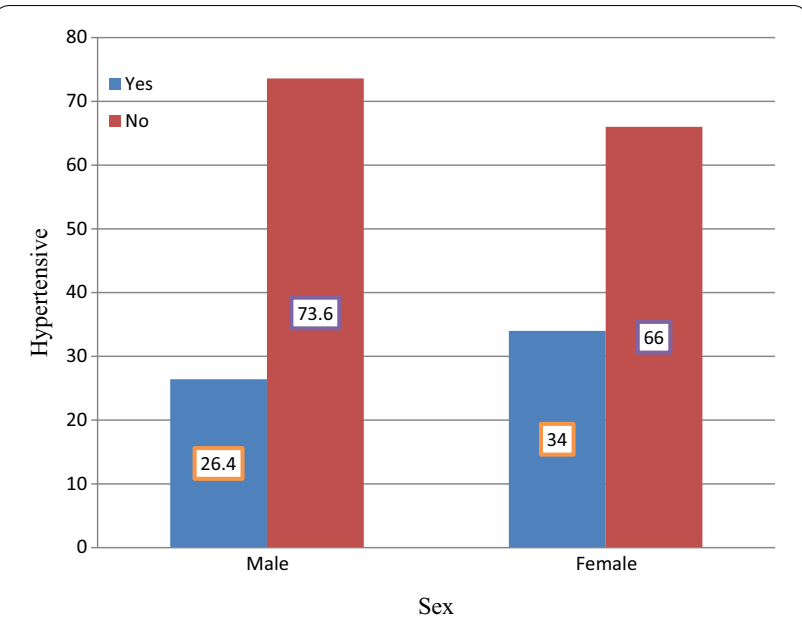

Fig. 1 Distribution of hypertension by sex of participants

The mean BMI of the study participants was $23.79 \pm 2.60 \mathrm{~kg} / \mathrm{m}^{2}$ (SD). Fifty-four (10.3\%) participants were overweight and 28 (5.3\%) were obese.

The mean waist circumference of men was $86.9 \pm 4.9 \mathrm{~cm}$ (SD). The vast majority $(84.1 \%)$ of men had waist circumference measurement of $\leq 94 \mathrm{~cm}$ whereas 36 (12.9\%) of them had $>94 \mathrm{~cm}$. Few, 3.0\%, of male participants had $>102 \mathrm{~cm}$ waist circumference measurement. The findings indicate that $12.9 \%$ men had increased risk for hypertension and metabolic complications.

The mean waist circumference for women was $83.6 \pm 8.35 \mathrm{SD} \mathrm{cm}$. One hundred four $(42.1 \%)$ women had waist circumference measurement of $<80 \mathrm{~cm}$. Nearly one out of three $(29.1 \%)$; women have waist circumference measurement of $>80 \mathrm{~cm}$. On the other hand, 71 (28.7\%) of women had waist circumference measurement of $>88 \mathrm{~cm}$. This finding represents that more than half of women had higher Waist circumference measurements. Twenty-nine percent of women had increased risk for hypertension and metabolic complications and $28.7 \%$ of women had substantially increased risk for hypertension and metabolic complications. Overall, 37.2\% (15.8\% men and $61.1 \%$ women) participants were identified as having increased risk for hypertension and metabolic complications.

\section{Physical activity}

Fifty-seven (10.9\%) and 108 (20.6\%) of the study participants undertake vigorous and moderate-intensity physical activities respectively. Only $22.9 \%$ of the participants reported the experience of aerobic physical activities. The average estimated time spent without movement among the study participants was $10.25 \pm 3.1$ (SD) hours. 


\section{Factors associated with hypertension}

The presence or absence of significant association between independent and outcome variables was determined. Accordingly, sex, marital status and aerobic physical activities were significantly associated with hypertension. The odds of hypertension was 1.92 times higher among men as compared to females (AOR 1.92; CI 1.14-3.23). The likelihood of hypertension was significantly higher among married participants when compared to unmarried ones (AOR 4.1; CI 1.0-16.18). Participants who did not undertake aerobic physical activities had three times more likely to develop hypertension as compared to participants who did (AOR 3.0; CI 1.1-6.5) (Table 2).

\section{Discussion}

The overall prevalence of hypertension in this study was $30.0 \%$. This is comparable with report from Addis Ababa (31.5\%) [25]. But higher than reported for Jimma town (13.2\%) [29], Gondar town (28.3\%) [12] and Sidama Zone (9.9\%) [30]. However, the prevalence of hypertension in our study was lower than the national average (35.2\%) [6] and Africa sub-regional prevalence $(47.5 \%)[9,10]$. The national average was higher because it used health facility reports in its estimation, which might have not represented the true magnitude in the general public. This difference could be explained by differences in life style factors including diet, exercise and the use of different substances, etc. Among hypertensive participants, those participants who are aware of their hypertensive status were $24.6 \%$, which matches with other study findings [ 28 , 29]. This might indicate low awareness and screening practices for hypertension in the community.

The prevalence of hypertension was significantly higher among men participants than females. In contrast, previous study reports showed that the variation in occurrence of hypertension between the two sexes was not statistically significant [12]. Conversely, the higher rate of hypertension among men in our study was congruent with previous study reports $[7,9,14,16]$. More likely, this difference could be explained as large number of men engage in risky behaviors such as excess alcohol consumption, smoking tobacco products, and ka'hat chewing that predispose to hypertension when compared to females. However, the controversy between reports on association between sex and hypertension warrant further study.

The prevalence of hypertension was found to be higher among higher age groups in previous studies [25, 29-31]. In our study age was obtained subjectively which might not be participants' exact age due to absence of birth certificates in majority of the cases. Although the risk of hypertension increased with advancing age because of biological reasons, substance use in younger age groups

Table 2 Bivariate and multivariate logistic regression analysis of factors associated with hypertension in Hosanna (n= 524), Ethiopia, 2014

\begin{tabular}{|c|c|c|c|c|c|}
\hline \multirow[t]{2}{*}{ Characteristics } & \multicolumn{2}{|c|}{ Hypertension } & \multirow[t]{2}{*}{ Bivariate OR $(95 \% \mathrm{Cl})$} & \multirow[t]{2}{*}{ Multivariate OR $(95 \% \mathrm{Cl})$} & \multirow[t]{2}{*}{ P-value } \\
\hline & Yes & No & & & \\
\hline \multicolumn{6}{|l|}{ Sex } \\
\hline Male & 73 & 204 & $1.4(0.99,2.06)$ & $1.92(1.14,3.23)$ & $0.014^{\dagger}$ \\
\hline Female & 84 & 163 & 1 & 1 & 0.00 \\
\hline \multicolumn{6}{|l|}{ Marital status } \\
\hline Single ${ }^{a}$ & 37 & 158 & 1 & 1 & 0.00 \\
\hline Married & 64 & 128 & $2.03(0.8,4.6)$ & $4.1(1.0,16.18)$ & $0.04^{+}$ \\
\hline Divorced & 46 & 60 & $0.95(0.4,2.14)$ & $1.7(0.3,7.3)$ & 0.46 \\
\hline Widowed & 10 & 21 & $0.62(0.2,1.4)$ & $1.2(0.18,7.8)$ & 0.80 \\
\hline \multicolumn{6}{|c|}{ Aerobic physical activity } \\
\hline Yes & 137 & 267 & 1 & 1 & 0.00 \\
\hline No & 20 & 100 & $2.5(1.5,4.32)$ & $3.0(1.4,6.5)$ & $0.004^{\dagger}$ \\
\hline \multicolumn{6}{|l|}{ Age group } \\
\hline $25-34$ & 19 & 83 & 1 & 1 & 0.00 \\
\hline $35-44$ & 75 & 198 & $0.6(0.3,1.06)$ & $0.4(0.23,0.81)$ & $0.01^{\dagger}$ \\
\hline $45-54$ & 54 & 56 & $0.2(0.12,0.4)$ & $0.1(0.04,0.25)$ & $<0.001^{\dagger}$ \\
\hline $55-64$ & 9 & 30 & $0.7(0.3,1.8)$ & $0.4(0.15,1.15)$ & 0.09 \\
\hline
\end{tabular}

$1=$ Reference

a Not ever married

+ P-value $<0.05$ 
balanced the prevalence of hypertension across all age groups. These facts could also, more likely, explain the importance of hypertension at any age.

In our study, marital status is significantly associated with hypertension and married participants were more likely to develop hypertension when compared to their unmarried counterparts. Community-based study in Jazan region of Saudi Arabia also reported the presence of association between marital status and hypertension [9]. This could be explained in such a way that married couples are vulnerable to and face disputes from different life dimensions. These stressful life conditions they may face could increase the risk of hypertension among them.

\section{Conclusion}

High prevalence of hypertension was noted among the study participants. Only few participants were aware of their hypertensive status. The community is at increased risk for hypertension and metabolic complications. Women had substantially increased risk for hypertension when compared to males. Sex, marital status and limited exercise were significantly associated with hypertension. Increased prevalence of hypertension and its associated factors imply the need for urgent intervention by designing strategies to increase public awareness on risks, preventive measures and screening behaviors.

\section{Limitations}

This study is cross-sectional; therefore, we cannot ascribe causality to any of the associated factors. Moreover, prevalence may not be representative as some severe cases may die soon after they develop the disease.

\begin{abstract}
Abbreviations
BMI: body mass index; Cl: confidence interval; CVD: cardiovascular disorders; DALY: disability adjusted life year; EDHS: ethiopia demographic and health survey; GPAQ: global physical activity questionnaire; HBP: high blood pressure; HSDP: health sector development; MMHG: millimeter mercury; NCD: noncommunicable diseases; PA: physical activity; SBP: systolic blood pressure; SSA: sub-Saharan Africa; WC: waist circumference; WHO: World Health Organization.
\end{abstract}

\section{Author's contributions}

LSA conceived and designed the study idea, developed proposal, organized the data collection tool, created data entry template, interpreted findings and wrote the manuscript. SYA edited the proposal and approved the manuscript. FLG edited the proposal and approved the manuscript. All authors read and approved the final manuscript.

\section{Author details}

${ }^{1}$ Department of Nursing, Hosanna College of Health Sciences, Post Box 159, Hosanna, Ethiopia. ${ }^{2}$ Department of Midwifery, Hosanna College of Health Sciences, Hosanna, Ethiopia. ${ }^{3}$ Hosanna College of Health Sciences, Hosanna, Ethiopia.

\section{Acknowledgements}

The authors would like to thank Hosanna College of Health Sciences Research and community service. We are also grateful to Hosanna town residents, data collectors and Hosanna town health office for their cooperation during the entire process of data collection.

\section{Competing interests}

The authors declare that they have no competing interests.

\section{Availability of data and materials}

Data will be obtained from the corresponding author whenever required.

\section{Consent for publication}

Not applicable.

\section{Ethical approval and consent to participate}

This study was approved by institutional review board of Hosanna College of Health Sciences. Informed verbal consent was obtained from all study participants before data collection after explaining the objectives of the research. In this research we obtained informed verbal consent from the research participants because all the data sought was associated purely with information rather than human samples or did not put participants on experiment, which needs national ethical approval in our context. We obtained ethical clearance for the research to be conducted in this way. This is the reason why we obtained informed verbal consent than written.

\section{Funding}

Hosanna College of Health Sciences funded the study. The funder had no role in study design, data collection and analysis, decision to publish, or preparation of the manuscript.

\section{Publisher's Note}

Springer Nature remains neutral with regard to jurisdictional claims in published maps and institutional affiliations.

Received: 3 March 2018 Accepted: 11 May 2018

Published online: 16 May 2018

\section{References}

1. US Department of Health and Human Service, National Institute of Health, National Heart, Lung, and Blood Institute, National High Blood Pressure Education Program. JNC-7: the seventh report of the national committee on prevention, detection, evaluation and treatment of high blood pressure. $\mathrm{NIH} ; 2003$.

2. Oparil S. Pathogenesis of hypertension. Ann Intern Med. 2003:139:761-70

3. National Heart Foundation of Australia: National Blood pressure and vascular diseases Advisory Committee. Guide to management of hypertension; 2008. www.heartfoundation.org.aupdf. Accessed 1 Jan 2014

4. Oparil S. Physiology in medicine: a series of Articles linking medicine with science: pathogenesis of hypertension. Anns Intern Med. 2003:139:761-76.

5. Maryon-Davis A. Faculty of public health of the royal colleges of physicians of UK hypertension - the silent killers; 2005. www.fph.org.ukpdf. Accessed 30 Dec 2013.

6. Alwan A. Global status report on non-communicable diseases 2010. Geneva, Switzerland: World Health Organization; 2010. p. 2-17.

7. Dreisbach AW. Epidemiology of hypertension. Meds cape drugs, diseases and procedure reference. 11 July 2013

8. Vijver SVD, Akiny H, Oti S, Olajide A, Agyemang C, Aboderin I, Kyobutungi C. Status report on hypertension in Africa-consultative review for the session of the African Union conference of minister's health on noncommunicable diseases. Pan Afr Med J. 2013;16:38.

9. Addo J, Smeeth L, Leon DA. Hypertension in sub-Saharan Africa: a systematic review. Hypertension. 2007:50:1012-8. https://doi.org/10.1161/ hypertensionAHA.107.09336.

10. Dzudie A, Kengere AP, Muna WFT, Ba H, Menanga A, Kouam CK, et al. Prevalence, awareness, treatment and control of hypertension in a selfselected Sub-Saharan African urban population: a cross-sectional study. BMJ Open. 2012. https://doi.org/10.1136/bmjopen-2012-001217.

11. Chelkeba L, Dessie S. Ant hypertension medication adherence and associated factors at Dessie Hospital, Northeast Ethiopia, Ethiopia. Int J Res Med Sci. 2013;1:191-7. https://doi.org/10.5455/2320-6012.ijrms20130802. 
12. Awoke A, Awoke T, Alemu S, Megabiaw B. Prevalence and associated factors of hypertension among adults in Gondar, Northwest Ethiopia: a community based cross-sectional study. BMC Cardiovasc Disord. 2012;12:113-7.

13. Esam SM, Husain AS. Prevalence of pre hypertension and hypertension in rural Bareilly. Nat J Med Res. 2012;2:291-4.

14. Ibrahim NKR, Hijazi NA, Al-Bar A. Prevalence and determinants of pre hypertension and hypertension among preparatory and secondary school teachers in Jeddah. J Egypt Public Health Assoc. 2008:83:184-203.

15. Tesfaye F, Byass P, Berhane Y, Bonita R, Wall S. Association of smoking and Khat (Catha-edulisForsk) use with high blood pressure among adults in Addis, Ethiopia. Prev Chronic Dis 2008;5. http://www.cdc.gov/pcd/issue s/2008/jul/07-0137html. Accessed 20 Feb 2014.

16. Ekwunife $\mathrm{O}$, Udeogaranya $\mathrm{P}, \mathrm{Nwatu} \mathrm{T}$. Prevalence, awareness, treatment and control of hypertension in a Nigerian population. Health. 2010;2:7315. https://doi.org/10.4236/health.2010.27111.

17. Pongwecharak J, Treeranurat T. Screening for pre-hypertension and elevated cardiovascular risk factors in a Thai community pharmacy. Pharm World Sci. 2010;32:329-33. https://doi.org/10.1007/s11096-010-9373-1.

18. Amira CO, Sokunbi DOB, Sokunbi A. The prevalence of obesity and its relationship with hypertension in an urban community: data from, world kidney day screening program. Int J Med Biomed Res. 2012;1:104-10.

19. Narksawat K, Chansatitporn N, Panket P, Hangsantea J. Screening high risk population for hypertension and type 2 diabetes among Thais. WHO South-east Asia. J Public Health. 2012;1:320-9.

20. John J, Muliyil J, Balraj V. Screening for hypertension among adults: a primary care is high risk approach. Indian J community Med. 2010;35:67-9. https://doi.org/10.4103/0970-0218.62561 html.

21. Sliwa K, Stewart S, Gersh BJ. Hypertension: a global perspective circulation. Hypertension. 2011;123:2892-6. https://doi.org/10.1161/circulatio naha.110992362.
22. Schutte AE, Schutte R, Huisman HW, Rooyen JM, Foume CMT, Malan NT, et al. Are behavioral risk factors to be blamed for the conversion of optimal blood pressure to hypertensive status in black South Africans? A 5-year prospective study. Int J Epidmiol. 2012;41:1114-23. https://doi. org/10.1093/IJE/DYS106.

23. WHO. 2008-2013 action plan for global strategy for the prevention and control of non-communicable diseases: Geneva: World Health Organization; 2008.

24. Queensland Health. The health of Queenslanders 2012: Advancing good health. Fourth report of the chief health officer Queensland. Brisbane, October 2012.

25. Tesfaye F, Byass P, Wall S. Population based prevalence of high blood pressure among adults in Addis Ababa: uncovering a silent epidemic. BMC Cardiovasc Disord. 2009;9:39.

26. CSA. Summary and statistical report of the 2007 population and Housing Census, Addis Ababa. Ethiopia: Population and Housing Census Commission; 2008 .

27. WHO. World health organization Global recommendation on physical activity for health. Geneva: World health organization; 2011. http://www. who.int/dietphysicalactivity/pa/en/index.html. Accessed 26 May 2014.

28. WHO. WHO STEPS approach to chronic disease risk factors surveillance (STEPS). Geneva: WHO; 2005. www.who.int/chp/stepspdf. Accessed 26 May 2014.

29. Gudina EK, Michael Y, Assegid S. Prevalence of hypertension and its risk factors in Southwest Ethiopia: a community based cross-sectional survey. Integr Blood Press Control. 2013;6:111-7.

30. Giday A, Taddese B. Prevalence and determinants of hypertension in rural and urban areas of southern Ethiopia. Ethiop Med J. 2011;49:139-47.

31. WHO. Global recommendations on physical activity for health. Geneva: World Health Organization; 2010.
Ready to submit your research? Choose BMC and benefit from:

- fast, convenient online submission

- thorough peer review by experienced researchers in your field

- rapid publication on acceptance

- support for research data, including large and complex data types

- gold Open Access which fosters wider collaboration and increased citations

- maximum visibility for your research: over $100 \mathrm{M}$ website views per year

At BMC, research is always in progress.

Learn more biomedcentral.com/submissions 